\title{
The art of converting molecules into machines: supramolecular chemistry
}

\section{Introduction}

A chemist is a designer and creator of molecules, materials and devices which are all useful to solve the problems of mankind. In every field of technology, miniaturisation of devices/machines is an important process and also need of the hour. More importantly, in living organisms, cells work as molecular machines to power our organs, regulate temperature and repair damage. ${ }^{1}$

Many inventions/ innovations have blow up as a result of putting nature's principle to use in laboratory and ultimately in the factory this is self-assembly due to molecular recognition, the science which refers to the spontaneous formation of organised assemblies. Number of complex but nano-sized machines is at work in our cells, bringing bio molecules together to create large .

\section{Supramolecular chemistry \& molecular ma- chines}

"Supramolecular chemistry is the interdisciplinary branch of science (connects Chemistry, Physics, Nano \& Biological sciences) which deals about the self assembly of structures and functions of the design/device created by inter molecular non-covalent interactions between few or more chemical units" (Figure 1). The art of creating/converting Molecules into Machines using non-covalent/ intermolecular interactions is the emerging field of science that has caught the attention of many, in the scientific community.

Molecular machines are incredibly small single-molecules that aren't much different from the machines people come across every day. They have controllable actions and can perform a task with the input of energy. They are one thousand times thinner than a strand of hair, their impact could be as big as the microchip, they could one day go to work in the human body and they could even detect diseases before we show any symptom.

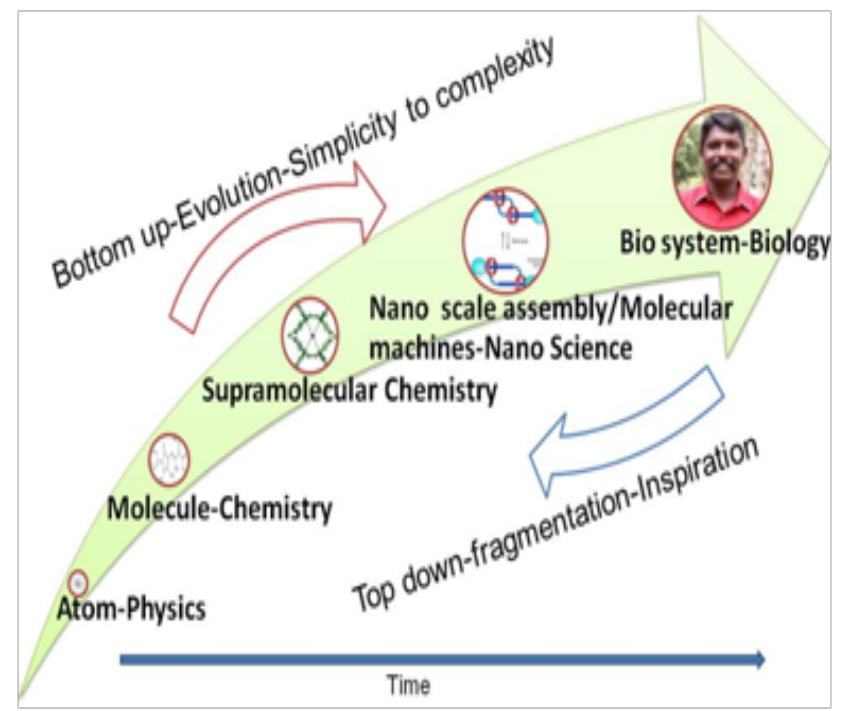

Figure I The connectivity between various subjects of science.
Volume I Issue 4 - 2017

Paulraj Mosae Selvakumar
Department of Chemistry, Karunya University, India

Correspondence: Paulraj Mosae Selvakumar, Department of Chemistry, Karunya University, Coimbatore, Tamil Nadu-64 I I 14, India,Email pmosae@gmail.com

Received: August 30, 2017| Published: September 0I, 2017

\section{Types of molecular machines}

Molecular machines can be divided into two broad categories; they are Synthetic and Biological

\section{Synthetic molecular machines}

Synthetic molecular machines consist of a single molecule; however, they are often constructed for mechanically-interlocked molecular assemblies, such as catenanes and rotaxane. From a synthetic viewpoint, there are two important types of molecular machines: molecular switches ${ }^{2}$ (molecule that can be reversibly shifted between two or more stable states) and molecular motors ${ }^{3}$ (molecules that convert chemical energy into mechanical movement).

Based on the function of the synthetic molecular machines, they can be classified as Molecular logic gates, ${ }^{4}$ Molecular Sensors, ${ }^{5}$ Assemblers, Shuttles, Tweezers, Rotors, Elevators, Valves, Transporters, Pumps, Lifts, Muscles, Nano cars ${ }^{6}$ etc.

Based on the input provided to make the molecule into machine, they can be classified into Chemical, Electro chemical, Photo chemical, $\mathrm{pH}$ and Temperature driven molecular machines. ${ }^{7}$

\section{Biological molecular machines}

Bacterial Flagellum, Eukaryotic Cilium, Aminoacyl-tRNA Synthetases (aaRS), Kinesin, Blood clotting cascade, Antibodies and the Adaptive Immune System, Calcium Pump, Tim/Tom Systems, Helicases and Ribosomes are a few important examples for the Biological Molecular machines. ${ }^{8}$ Cell is a basic unit of any species. The whole cell can be viewed as a factory that contains an elaborate network of interlocking assembly lines, each of which is composed of a set of large protein machines. ${ }^{1}$

\section{Supramolecular chemistry-the art of conver- ting molecules into machines}

Starting from atoms and molecule, the bottom-up approach was proposed by Richard Feynman, in 1960. Around the 1980s, supramolecular chemistry evolved as a discipline which exploits basic concepts such as molecular recognition, coopertivity, self-assembly, self-organization, and self-replication that are central to nature's forms and functions. In the 1990s, these concepts became feasible to 
construct large and complex, yet highly well-organized, functioning molecular and supramolecular units by recognizing the significance of mechanical as well as noncovalent and, of course, covalent bonds. Catenanes, Pseudorotaxanes and rotaxanes are attractive examples of such entities (Figure 2).

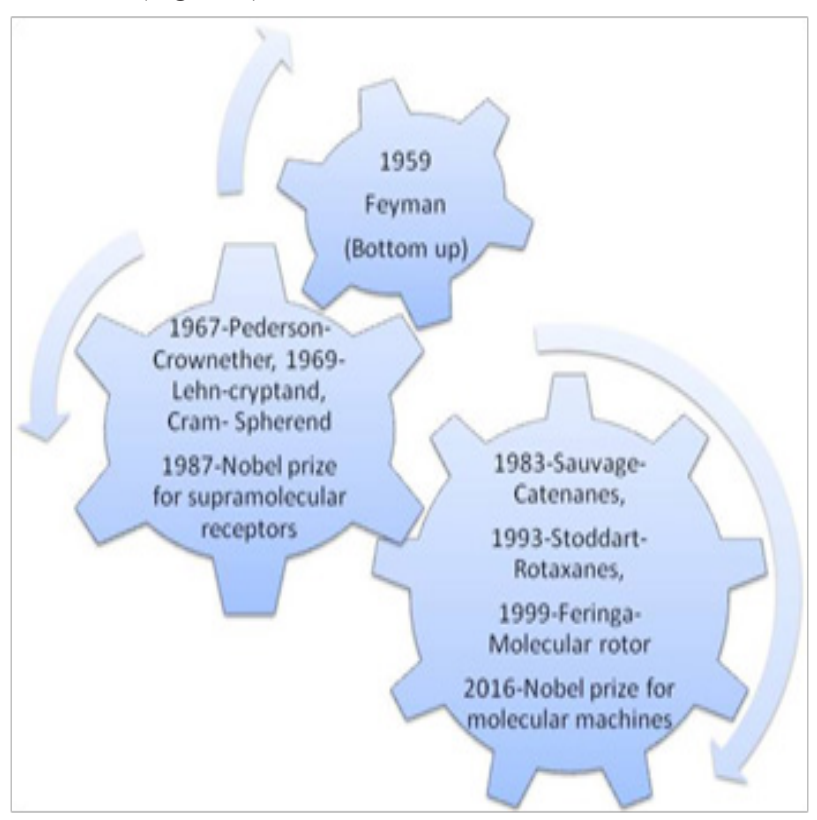

Figure 2 Scientific Journey towards molecular machines.

\section{Journey from molecules to machines: noble prize | 987 and $20 \mid 6$}

The Nobel Prize in Chemistry for 1987 was awarded jointly to Donald J. Cram, Jean-Marie Lehn and Charles J. Pedersen for their development and use of molecules with highly selective structure specific interaction, i.e. molecules that can recognize each other and choose with which other molecules they will form complexes. ${ }^{9}$ Molecules have been produced that mimic the mode of action of enzymes.

In 1967, Charles J. Pedersen designed the cyclic polyethers (crown ethers) which can bind the alkali metal ions specifically with high selectivity. By building on Pedersen's basic discovery, Jean-Marie Lehn in 1969 developed bicyclic compounds of crown ether type called as cryptands. Jean-Marie Lehn and Donald J. Cram have subsequently each developed spherends, which when forming complexes leave fissures and cavities where low-molecular-weight compounds with different types of geometry can be bound. With this work, Cram has coined the term host-guest chemistry while Lehn calls it supramolecular chemistry ${ }^{10}$ which led to the development of molecular machines.

\section{Development of world's smallest machines- -noble prize in chemistry 2016}

The Nobel Prize in chemistry for 2016 is awarded to Jean-Pierre Sauvage, Sir J Fraser Stoddart and Bernard L. Feringa for their design and development of molecular machines. ${ }^{11}$ They have developed molecules with controllable movements, which can perform a task when energy is added. The first step towards a molecular machine was taken by Professsor Sauvage in 1983, when he succeeded in linking two ring-shaped molecules together to form a chain, called a catenane. The second step was taken by Professor Fraser Stoddart in 1991, when he developed a rotaxane. ${ }^{12}$ He threaded a molecular ring onto a thin molecular axle and demonstrated that the ring was able to move along the axle. Among his developments based on rotaxanes are a molecular lift, a molecular muscle and a molecule-based computer chip. Bernard Feringa ${ }^{13}$ was the first person to develop a molecular motor; in 1999 he got a molecular rotor blade to spin continually in the same direction. Using molecular motors, he has rotated a glass cylinder that is 10,000 times bigger than the motor and also designed a nanocar.

Apart from the above mentioned Nobel laureates, Many scientists from various research groups such as V Balzani, D A Leigh, A Credi, Crommie, N Katsonis, R A Milligan, Hafen, Kay, Hecht, Dichtel, T Böcking, Davis, Deindl, Crowley and A CiQUS ,SAMS, MIT media lab research groups \&etc. are working towards developing various types of nano-sized molecular machines which are all going to be the part of the life of our future generations.

\section{Conclusion and outlook}

Synthetic supramolecular assemblies have found their inspiration in biological systems. The concept of molecular machine and correlation of biological system with molecular machine thus can also be useful to understand the evolution of life. The host-guest systems and synthetic supramolecular architectures can bridge the gap between small molecules, polymers, molecular machines and the complex framework of a biological cell. The chemistry-2016 Nobel laureates were among the first to replicate machine work in synthetic molecules, by functioning out how to convert chemical energy into mechanical action. This allowed them to build molecular devices a many thousand times smaller than the width of a human hair, including switches, motors, shuttles and even something resembling a lift, muscle and motorcar. Around the world many scientists are involved in the construction of molecular machines for the specific function. Ever since the introduction of the term "molecular machine", the research in this field has intensified and the number of publications has been increasing. The Scopus ${ }^{14}$ keyword search indicates that 26,113 documents were published up to date with the keyword "Molecular machines". It is evidence that "molecular machines" have become a hot research area in the scientific community. Up to date, two patents were granted on molecular machines ${ }^{15,16}$ (US 7964722 B2, WO 2017011870 A1). These information increases our confidence on the usage of molecular machines at our homes for doing work in future.

\section{Acknowledgements}

None.

\section{Conflict of interest}

The author declares no conflict of interest.

\section{References}

1. Alberts B. The Cell as a Collection of Protein Machines: Preparing the Next Generation of Molecular Biologists. Cell. 1998;92(3):291-294.

2. Ballardini R, Balzani V, Credi A, et al. Artificial Molecular-Level Machines: Which Energy To Make Them Work? Acc Chem Res. 2001;34(6):445-455.

3. Kay ER, Leigh DA, Zerbetto F. Synthetic Molecular Motors and Mechanical Machines. Angew Chem Int Ed Engl. 2007;46(1-2):72-191. 
4. Yousuf S, Alex R, Selvakumar PM, et al. Picking Out Logic Operations in a Naphthalene $\beta$-Diketone Derivative by Using Molecular Encapsulation, Controlled Protonation, and DNA Binding. Chemistry Open. 2015;4(4):497-508.

5. Selvan GT, Kumaresan M, Sivaraj R, et al. Isomeric 4-aminoantipyrine derivatives as fluorescent chemosensors of $\mathrm{Al}^{3+}$ ions and their molecular logic behaviour. Sensors and Actuators B: Chemical. 2016;229:181189.

6. Cheng C, Stoddart JF. Wholly Synthetic Molecular Machines. Chem Phys Chem. 2016;17(12):1780-1793.

7. Erbasm-Cakmak S, Leigh DA, McTernan CT, et al. Artificial Molecular Machines. Chem Rev. 2015;115(18):10081-10206.

8. Piccolino M. Biological machines: from mills to molecules. Nat Rev Mol Cell Biol. 2000;1(2):149-153.

9. https://www.nobelprize.org/nobel_prizes/chemistry/laureates/1987/ press.html
10. https://www.nobelprize.org/nobel prizes/chemistry/laureates/2016/ press.htm

11. Lehn JM. Supramolecular Chemistry: Concepts and Perspectives. Germany: VCH Weinheim; 1995.

12. Jiménez MC, Dietrich-Buchecker C, Sauvage JP. Towards synthetic molecular machines: Contraction and stretching of a linear rotaxane dimer. Angew Chem Int Ed Engl. 2000;39(18):3284-3287.

13. Wesley RB, Feringa BL. Making molecular machines work. Nat Nanotechnol. 2006;1(1):25-35.

14. www.scopus.com

15. Bell TW, Joseph CI, Christine RC, et al. Light-driven rotary molecular motors. 2011. US 7964722 B2.

16. Scott C, Hartley C, Williams C, et al. Molecular machines. 2017. WO 2017011870 A1. 